\title{
Influence of Hygrothermal Environment on Absorption and shear strength of CF3031/CCF300 stiffened composite panel
}

\author{
Xiaopeng Shi ${ }^{a}$, Shulin $\mathrm{Li}^{\mathrm{b}}$, Fei Chang ${ }^{\mathrm{c}}$, Junjie Yin ${ }^{\mathrm{d}}$ \\ Air Force Engineering University, Aeronautics and Astronautics Engineering College, Xi'an 710038, \\ China

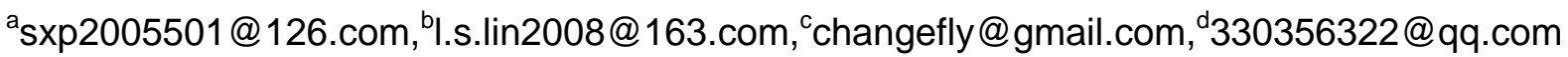

Keywords: stiffened composite panel; absorption; hygrothemal aging; shearing properties; glass transition temperature.

\begin{abstract}
Focus on the hygrothermal environment problems of CF3031/CCF300 stiffened composite panel, the stiffened composite panel absorption were studied on in the $85 \% \mathrm{RH}, 70^{\circ} \mathrm{C}$ hygrothermal environment, the moisture equilibrium content of the composites were calculated. The shear test were carried on after hygrothermal aging, observed the change of the strain, and draw the conclusion of the flexural load and the breaking load, contrasted with the panel of before hygrothemal aging. The results show that the shear strength was correlated with glass transition temperature, and the rate of remained flexural load was about $85 \%$ and the rate of remained breaking load was about $75 \%$ after hygrothemal aging.
\end{abstract}

\section{Introduction}

Composites, owing to their inherently high specific mechanical properties, are widely used as primary structures in many areas such as aerospace, sport equipment, pressure vessels and automobile parts. Structures used in the above fields are more often exposed to high temperature as well as moisture. Environmental conditions due to moisture absorption and temperature seem to have a significant effect on the stiffness and strength of the structural composites. So it is necessary to study on the hygrothermal aging during the service life of composites.

In recent years, considerable amount of work on the stability behavior of laminated composite plates subjected to thermal moisture absorption or mechanical loadings has been carried out by many researchers [1-4]. Moreover, the increase in moisture and temperature reduces the elastic modulus of the material and a considerable transient stresses are induced; consequently the durability as well as the safety of the structures are affected [5-8].

In this way, various studies have shown the combined effect of the moisture and temperature on composite tensile strength and modulus. Almen et al. [9] presented the study of CFRP woven composite degradation properties in hot/wet environments. Shen and Springer [10] established a study on moisture related degradations in tensile strength and stiffness of $0^{\circ}$ and $45^{\circ}$ carbon/epoxy composites to be independent of temperature. The research of Guo Li-mei et al.[11] have indicated that the main ageing mechanisms of those composites are plasticization effect of water absorbed on the matrix and micro-cracking due to the stress resulting from the mismatch of the moisture expansions between the matrix and carbon fibers. Liu Jian-dong et al.[12] have studied on the mechanics of T300/5405 composite. They indicated that the mechanics had declined after hygrothermal aging.

In this paper, the absorbed behavior of stiffened composite panel in hygrothermal environment had been studied. Then we conducted same tests on the panels which were absorbed equilibration, and the hygrothermal environment effect on shear strength of stiffened composite panel had been studied. 


\section{Tests}

\section{Test specimen materials.}

In this paper, the materials of experiment are CCF300/5428. Each of the thickness of lamina is $0.125 \mathrm{~mm}$. The stiffener of the composite is in appearance. And they are connected with skin. The size of construction specimens is $550 \mathrm{~mm} * 550 \mathrm{~mm} * 2.75 \mathrm{~mm}$. The material properties of CCF300/5428 are shown in Table 1.

Tab.1 the material properties of CCF300/5428

\begin{tabular}{cccc}
\hline$E_{1} / \mathrm{MPa}$ & $E_{2} / \mathrm{MPa}$ & $E_{3} / \mathrm{MPa}$ & $v_{12}$ \\
\hline 154000 & 9750 & 9750 & 0.32 \\
\hline$v_{13}$ & $v_{23}$ & $G_{12} / \mathrm{MPa}$ & $G_{13} / \mathrm{MPa}$ \\
\hline 0.32 & 0.45 & 6500 & 6500 \\
\hline$G_{23} / \mathrm{MPa}$ & $X_{t} / \mathrm{MPa}$ & $Y_{t} / \mathrm{MPa}$ & $X_{c} / \mathrm{MPa}$ \\
\hline 3800 & 1988 & 78 & 1318 \\
\hline$Y_{c} / \mathrm{MPa}$ & $S_{12} / \mathrm{MPa}$ & $S_{13} / \mathrm{MPa}$ & $S_{23} / \mathrm{MPa}$ \\
\hline 229 & 102 & 110.5 & 110.5
\end{tabular}

\section{Moisture absorbed test.}

Put the construction specimen into oven to dry in $70^{\circ} \mathrm{C}$, and make the specimen be oven-dry equilibrium (the mass lost is less than $0.02 \%$ ). Then record the oven-dry specimens mass as the baseline mass and place the specimens pretreated in conditioning chamber to carry on the hygrothermal aging test.

The apparatus of conditioning chamber is GDJS-1000 which can carry on the alternating temperature between high and low temperature in moisture condition. The main parameters are $-20 \sim 150^{\circ} \mathrm{C} / 30 \% \sim 98 \% \mathrm{RH}$, temperature fluctuation is $\pm 0.5^{\circ} \mathrm{C}$, furthermore the moisture fluctuation is $+2 \sim-3 \% \mathrm{RH}$. The test environment is $70^{\circ} \mathrm{C} / 85 \% \mathrm{RH}$.

During the hygrothermal test, the mass of specimens should be recorded every day. The test method conform to ASTM D 5229/D 5229M-92(04) standard (standard test method for moisture absorption properties and equilibrium conditioning of polymer matrix composite materials). The specimens are divided into 3 groups. Estimate the absorption level through measuring the mass of traveler coupon. The calculate method is shown as follows:

$$
M_{t}=\left(\left(W_{i}-W_{0}\right) \times 100 \%\right) / W_{0}
$$

Where:

$M_{t}$ is current moisture content (\%); $W_{0}$ is the mass of oven-dry traveler coupon (g); $W_{i}$ is current traveler coupon mass.

\section{Shear test.}
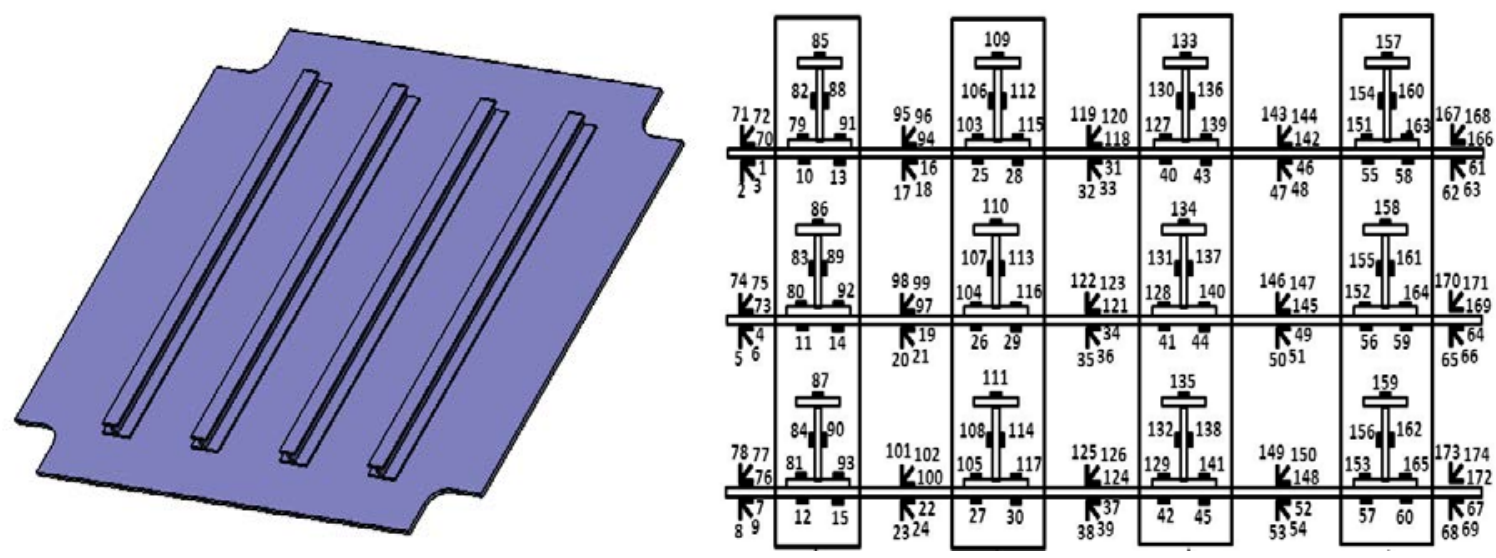

Fig.1 position of strain gauges

The apparatus of shear test is YAW-5000F. The test method conform to HB7237 standard. Before testing, the specimens should be detection and record the surface imperfection. Then strain gauges are sticked to the each specimen. The position of strain gauges is shown in Fig.1. Meanwhile, debug 
the strain measurement and loading device. Then set up the specimen on the shear test apparatus. After that, according to the scheduled loader to increase load. During the shear test, record the strain under per load level and obtain the strain distribution and strain-load curves.

\section{Test results and discussion}

\section{Moisture absorption analysis.}

Moisture content of the specimens can be calculated by Eq. 1and the absorption curves are shown in Fig. 2. Form Fig. 2 we can divided the curves into 2 parts, linearity increase part and moisture equilibrium part.

The material absorption behaves according to Fick's low:

$\frac{\partial c}{\partial t}=D_{z} \frac{\partial^{2} c}{\partial z^{2}}$

Where:

$\mathrm{C}=$ specimen moisture concentration, $\mathrm{g} / \mathrm{mm}^{3}$;

$D_{z}=$ Fickian material diffusion constant through-the-thickness of the material, $\mathrm{mm}^{2} / \mathrm{s}$

$z=$ through-the-thickness direction, $\mathrm{mm}$.

And the diffusivity ${ }^{D_{z}}$ can be calculated as follows:

$D_{x}=\pi\left(\frac{h}{4 M_{\infty}}\right)^{2}\left(\frac{M_{2}-M_{1}}{\sqrt{t_{2}}-\sqrt{t_{1}}}\right)^{2}$

Where:

$h=$ average specimen thickness, $m m ; M_{\infty}=$ effective moisture equilibrium content, \%. $\frac{M_{2}-M_{1}}{\sqrt{t_{2}}-\sqrt{t_{1}}}=$ slope of moisture absorption plot in the initial linear portion of the curve, $\sqrt{\operatorname{seconds}}^{-1}$

The diffusivity $D_{z}=0.0316 \mathrm{~mm}^{2} /$ day based on test data.

Moisture content ${ }^{M_{t}}$ at every time can be defined by FICK law:

$M_{t}=M_{m}\left[1-\frac{8}{\pi^{2}} \sum_{n=0}^{\infty} \frac{\exp \left[(2 n+1)^{2} \pi^{2}\left(-\frac{D t}{h^{2}}\right)\right]}{(2 n+1)^{2}}\right]$

From Eq. (4), the curves between moisture content $M_{t}$ and time $\sqrt{t}$ can be drown, which is shown in Fig.2. From Fig.2, we can conclude that: moisture content $M_{t}$ change linearity with time $\sqrt{t}$ increasing at the absorption initial stage. However, the speed of moisture absorption become slower and slower at the absorption later stage. At last, the moisture content tend to equilibration.

In order to contrast the test date and Fick law, the absorption curves of test and Fick law are drown in the same figure which is shown in Fig. 2.

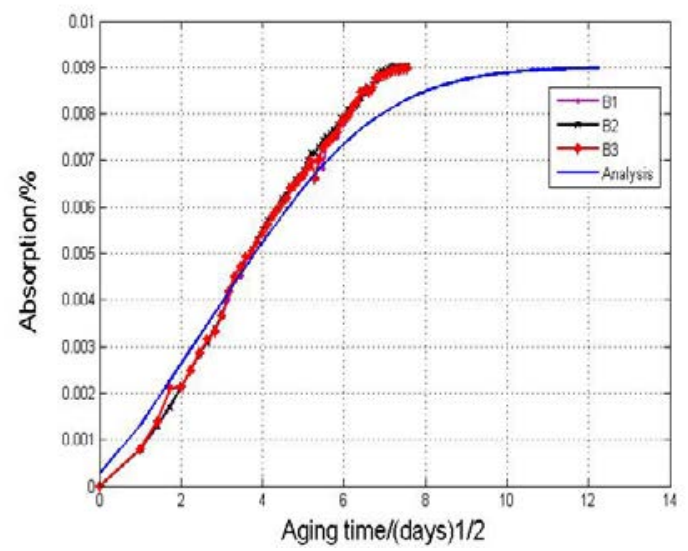

Fig.2 Moisture absorption curves of experiments and analysis 
From the figure, we can conclude that the moisture absorption curves of test and analysis are fitted better at the initial stage. That is to say, test data obey to Fick's law. The moisture content is proportional to square of aging time; however, after long-term of moisture absorption, the increase of moisture content becomes slower. At this stage there are some different form the moisture absorption curves of test and analysis. Furthermore, the moisture content tends to a stable value which is moisture equilibrium content of composite in the hygrothermal environment (from the standard of ASTM D 5229, when $\left|M_{i}-M_{i-1}\right|<0.01 \%$, the moisture absorption is equilibrium). When the aging time is about $\mathrm{t} 1 / 2=7$, the moisture content is equilibrium.

The equilibration moisture content of each group is shown as follows:

$\mathrm{M}_{\mathrm{m}}^{1}=0.898 \% ; \mathrm{M}_{\mathrm{m}}^{2}=0.898 \% ; \mathrm{M}_{\mathrm{m}}^{3}=0.901 \%$

\section{Shear property analysis.}

The shear carrying capacity of stiffened composite panel before and after hygrothermal aging is obtained from the test. In order to analysis the change of different positions' strain in the loading progress, both hygrothermal aging specimen'(A-1) and non-hygrothermal aging specimen'(B-1) force-strain curves are drown. Those are shown in Fig.3 and Fig.4.

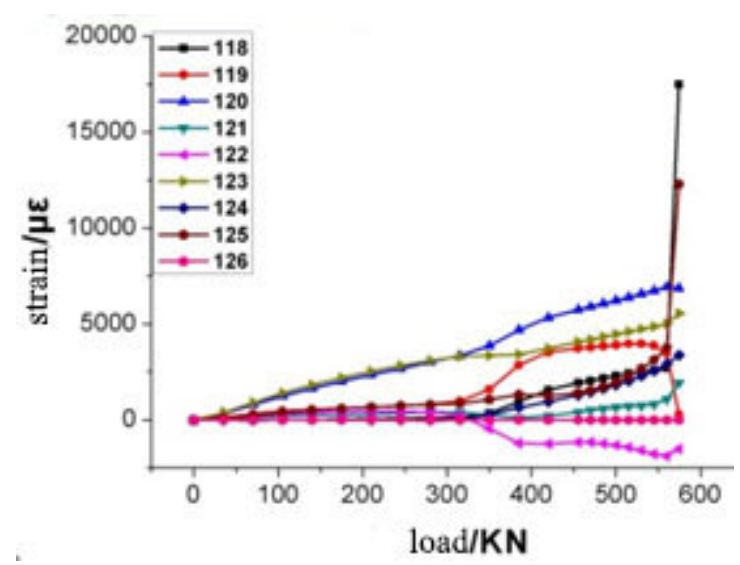

Fig 3 force-strain curves after hygrothemal aging

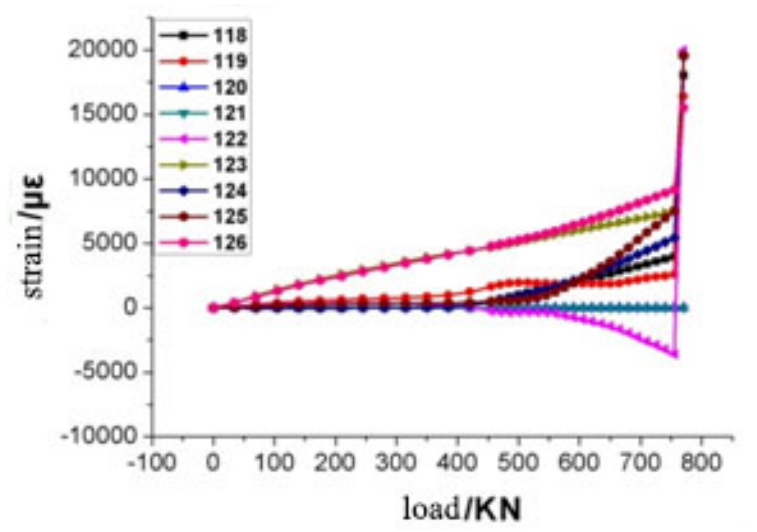

Fig 4 force-strain curves before hygrothemal aging

From those figures, we can conclude that the strain curves have an inflection-point when the load up to $350 \mathrm{KN}$ for hygrothermal aging specimen, that is to say buckling has occurred at this load level. However, the buckling load is $450 \mathrm{KN}$ for non-hygrothermal aging specimen. And the breaking load is $570 \mathrm{KN}$ and $750 \mathrm{KN}$ for hygrothermal and non-hygrothermal aging specimen respectively. The bucking load is $61.4 \%$ of the breaking load for hygrothermal aging specimen and the bucking load is $60 \%$ of the breaking load for non-hygrothermal aging specimen. So after the specimen buckling, they still have great carrying capacity.

The shear carrying capacity of hygrothermal aging specimen and non-hygrothermal aging specimen are shown in Tab.2. 
Tab.2 the shear carrying capacity of the testing

\begin{tabular}{cccccc}
\hline & Number & Flexural load & $\begin{array}{c}\text { The average of } \\
\text { Flexural load }\end{array}$ & $\begin{array}{c}\text { Breaking } \\
\text { load }\end{array}$ & $\begin{array}{c}\text { The average of } \\
\text { breaking load }\end{array}$ \\
\hline $\begin{array}{c}\text { Before } \\
\text { hygrothemal }\end{array}$ & B-1 & $450 \mathrm{KN}$ & & $750 \mathrm{KN}$ & \\
aging & $\mathrm{B}-2$ & $430 \mathrm{KN}$ & $442 \mathrm{KN}$ & $770 \mathrm{KN}$ & $764 \mathrm{KN}$ \\
\hline After & $\mathrm{B}-3$ & $445 \mathrm{KN}$ & & $772.4 \mathrm{KN}$ & \\
hygrothemal & $\mathrm{A}-1$ & $350 \mathrm{KN}$ & & $570 \mathrm{KN}$ & \\
aging & $\mathrm{A}-2$ & $360 \mathrm{KN}$ & $360 \mathrm{KN}$ & $574.5 \mathrm{KN}$ & $558 \mathrm{KN}$ \\
\hline
\end{tabular}

Tab.2 shows that the average of buckling load is $442 \mathrm{KN}$ for non-hygrothermal aging specimen, and the average of breaking load is $764 \mathrm{KN}$. However, the average of buckling load is 360KN for hygrothermal aging specimen, and the average of breaking load is $558 \mathrm{KN}$. The average of buckling load and the average of breaking load for hygrothermal aging specimen are lower than non-hygrothermal aging specimen. That is to say, after hygrothermal aging, the shear strength is reduced.

Shearing test date contrast between before and after hygrothemal aging is shown in Fig.5.

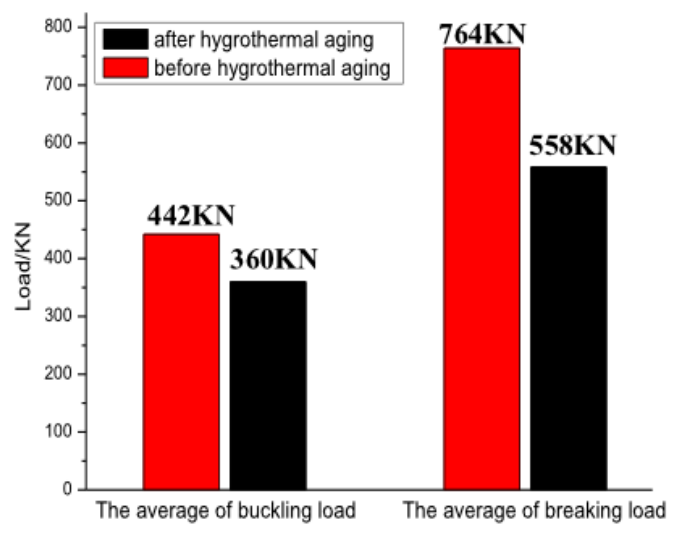

Fig. 5 shearing test date contrast between before and after hygrothemal aging

Fig. 5 shows that, both the buckling load and the breaking load are declined after hygrothermal aging. The buckling load and breaking load retention rate is $81.4 \%$ and $73 \%$ respectively.

The form of breaking after shear test is brittle failure. When the specimens broke, the surface of skin is cracking. Furthermore, the joint of stiffener and the skin is debonding. The stiffener is destroyed. The breaking form is shown in Fig.6.
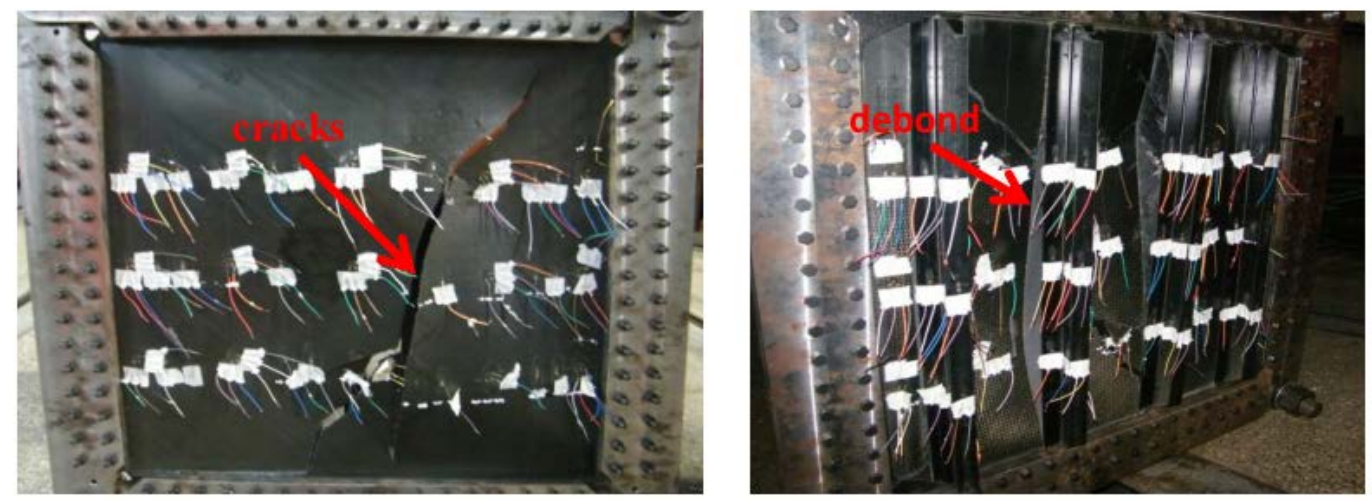

Fig 6 the breaking form of the testing

\section{Discussion.}

The hygrothermal aging process of fiber reinforced resin matrix composites is a joint action of temperature and moisture and stress. The degradation mechanism is acted on fiber and matrix and interface, at the same time, physics-chemistry changes are caused because of hygrothermal aging. In the moisture absorption process, the swelling stress will be emerged in the interior of structure. Furthermore, the swelling stress will increase bigger at the thermal impacting. When the swelling 
stress achieves to a certain value because of the interior stress increasing repeatedly, the cracks will be emerged. Consequently, the mechanical property of composites will be affected.

Because of the existence of influence on fiber and matrix and interface after hygrothermal aging, the strength between the layers and the breaking stress and stiffness under compression are degraded. Thereby, the buckling load and shear carrying capacity are degraded.

\section{Conclusions}

After about 60 day's hygrothermal aging process under $70^{\circ} \mathrm{C} / 85 \% \mathrm{RH}$ environment, the stiffened composite panels are up to moisture absorption equilibration. And the equilibration moisture content is about $0.9 \%$.

The bucking load is $64.5 \%$ of the breaking load for hygrothermal aging specimen and the bucking load is $57.8 \%$ of the breaking load for non-hygrothermal aging specimen.

Both the buckling load and the breaking load are declined after hygrothermal aging. The buckling load and breaking load retention rate is $81.4 \%$ and $73 \%$ respectively.

\section{References}

[1] Weaver, P. M., and Nemeth, M. P. Bounds on flexural properties and buckling response for symmetrically laminated composite plates. J. Engrg. Mech. 2007; 133(11):1178-1191.

[2] Onkar, A. K., Upadhyay, C. S., and Yadav, D. Stochastic finite element buckling analysis of laminated plates with circular cutout under uniaxial compression. J. Appl. Mech. 2007; 74:798-809.

[3] Shukla, K. K., Nath, Y., Kreuzer, E., and Sateesh Kumar, K. V. Buckling of laminated composite rectangular plates. J. Aerosp.Eng.2005; 18(4):215-223.

[4] Shukla, K. K., Huang, J. H., and Nath, Y. Thermal postbuckling of laminated composite plates with temperature dependent properties. J. Engrg. Mech.2004; 1307:818-825.

[5] Tsai, S.W.: Composite Design, 4th edn. Think Composites, Dayton (1988)

[6] Hahn, H.T., and Kim, R. Y.: Adv. submitted to Compos. Mater.-Environ. Eff. (1978)

[7] Springer, G.: Environmental Effects on Composite Materials (1981), p.166

[8] Nairn, J.A., Han, M.H.: submitted to Composites, Part A, (2003)

[9] Almen, G., MacKenzie, P., Malhotra, V., Maskell, R.: 977: characterization of a family of new toughened epoxy resins. In: 35th International SAMPE Symposium, pp. 419-431 (1990)

[10] Shen, C., Springer, G.S.: Effects of moisture and temperature on the tensile strength of composite materials. In: Environmental Effects on Composite Materials, pp. 79-93. Technomic, Westport (1981)

[11] GUO Mei-li, ZHAO Yan, XIE Ling. Study on hygrothermal aging mechanisms of aerospace structural composites[J]. Aerospace Materials \& Technology, 2002(4):51-54.

[12] LIU Jian-hua, CAO Dong, ZHANG Xiao-yun. Influence of Hygrothermal Environment on Absorption and Mechanical Properties of Advanced Composite T300/5405 [J]. JOURNAL OF AERONAUTICAL MATERIALS, 2010,27(5):142-149. 